\title{
Publisher Correction: Ellipticity dependence of high-harmonic generation in solids originating from coupled intraband and interband dynamics
}

\author{
Nicolas Tancogne-Dejean (1) 1,2, Oliver D. Mücke (1) 3,4, Franz X. Kärtner ${ }^{3,4,5}$ \& Angel Rubio (1) 1,2,3,5
}

Nature Communications 8:745 doi:10.1038/s41467-017-00764-5; Article published online: 29 Sep 2017

The published version of this Article contained an error in the second sentence of the fourth paragraph of the subheaded section "Ellipticity and helicity of the emitted harmonics". The final exponent in this sentence should read: in ${ }^{2} / 2$. This has now been corrected in the PDF and HTML versions of the Article.

Published online: 30 November 2017

\begin{abstract}
(c) (i) Open Access This article is licensed under a Creative Commons Attribution 4.0 International License, which permits use, sharing, adaptation, distribution and reproduction in any medium or format, as long as you give appropriate credit to the original author(s) and the source, provide a link to the Creative Commons license, and indicate if changes were made. The images or other third party material in this article are included in the article's Creative Commons license, unless indicated otherwise in a credit line to the material. If material is not included in the article's Creative Commons license and your intended use is not permitted by statutory regulation or exceeds the permitted use, you will need to obtain permission directly from the copyright holder. To view a copy of this license, visit http://creativecommons.org/licenses/by/4.0/.
\end{abstract}

(c) The Author(s) 2017

\footnotetext{
${ }^{1}$ Max Planck Institute for the Structure and Dynamics of Matter, Luruper Chaussee 149, 22761 Hamburg, Germany. ${ }^{2}$ European Theoretical Spectroscopy Facility (ETSF), Luruper Chaussee 14922761 Hamburg, Germany. ${ }^{3}$ Center for Free-Electron Laser Science CFEL, Deutsches Elektronen-Synchrotron DESY, Notkestraße 85, 22607 Hamburg, Germany. ${ }^{4}$ The Hamburg Center for Ultrafast Imaging, Luruper Chaussee 149, 22761 Hamburg, Germany. ${ }^{5}$ Physics Department, University of Hamburg, Luruper Chaussee 149, 22761 Hamburg, Germany. Correspondence and requests for materials should be addressed to N.T.-D. (email: nicolas.tancogne-dejean@mpsd.mpg.de) or to A.R. (email: angel.rubio@mpsd.mpg.de)
} 